\title{
The prosody of specification: Discourse intonational cues to setting up a variable
}

\author{
Wout Van Praet ${ }^{\text {a, b, * }}$, Gerard O'Grady ${ }^{c}$ \\ a UNamur, Unité d'Anglais, Rue de Bruxelles 61, B-5000, Namur, Belgium \\ ${ }^{\mathrm{b}}$ KU Leuven, Department of Linguistics, Blijde Inkomststraat 21, Box 3308, B-3000, Leuven, Belgium \\ ${ }^{\mathrm{c}}$ Cardiff University, John Percival Building (room 3.59), Colum Drive, Cardiff, CF10 3EU, United Kingdom
}

\section{A R T I C L E I N F O}

\section{Article history:}

Received 23 January 2018

Received in revised form 28 July 2018

Accepted 30 July 2018

\section{Keywords:}

Specificational copular clauses

Prosody

Information structure

\begin{abstract}
A B S T R A C T
While much research exists on specificational clauses, this paper is the first to systematically use real corpus examples to examine the meaning potential of prosody in signalling informational value in specificational clauses. Carefully distinguishing between two senses of information structure - the relational and the referential - we show that the interplay of prosody and specificational clause, reversed and non-reversed, is far from random. In the majority of non-reversed clauses, we found that the value and variable were realised in different tone units. Thus, claims that the value will receive the focal accent were found to be overly simplistic. Instead, where the variable and value were realised across different tone units the prosodic choice was motivated by the variable's discourse status and relative unpredictability. Rising tones presented the value as non-exhaustive, allowing for multiple values for a single variable. This re-enforced the projected lack of epistemic certainty. As expected, reversed specificationals were found to be produced mostly as single tone units; contrary to expectation, their focal accent was often on the variable. This, we noted, was likely due to the high incidence of demonstrative values in subject position. To conclude, our innovative approach demonstrates the importance of examining the interplay between syntax, discourse and prosody in explicating the meaning potential of constructions such as specificational clauses.
\end{abstract}

() 2018 Published by Elsevier B.V.

\section{Introduction}

Specificational copular clauses, first introduced (in those terms) by Akmaijan (1979), have been a rewarding subject for discussion for many years. Their function is to specify a value, e.g. Darryl Wakelin in (1), for a variable, e.g. the winner.

(1) The envelope please $\ldots$ and the winner is ... Darryl Wakelin. $\left(\mathrm{WB}^{1}\right)$

\footnotetext{
* Corresponding author. UNamur, Unité d'Anglais, Rue de Bruxelles 61, B-5000 Namur, Belgium.

E-mail addresses: wout.vanpraet@unamur.be (W. Van Praet), OGradyGN@cardiff.ac.uk (G. O'Grady).

${ }^{1}$ Examples followed by (WB) were extracted from WordbanksOnline and are reproduced here with the permission of HarperCollins. Examples followed by (LLC) are from the London Lund Corpus of Spoken English.
} 
The variable presupposes the existence of a specific instance, whose identity is revealed by the value. The variable itself is not sufficiently informative to enable the hearer to identify a concrete spatio-temporal instance: it merely gives a generalised description that outlines the contextually relevant features to which the specific value must conform. ${ }^{2}$ In (1), for instance, the variable establishes that there is a winner but does not tell the hearer who the winner is. As such, it has 'variable' reference, implicitly evoking a list of potential referents (i.e. 'competitor values'), from among which the value picks out one - e.g. Darryl Wakelin - as being the actual referent satisfying the variable. If the variable is definite as in (1), the value is specified as the only one corresponding to the variable. If the variable is indefinite as in (2), the speaker allows for the possibility that multiple values correspond to the same variable: in (2), for instance, the speaker asserts the existence of an indefinite number of 'codes that have to be followed', of which s/he specifies two, e.g. you do not kill and that you do not take drugs in sport.

(2) There are codes that have to be followed. One is you do not kill. Another is that you do not take drugs in sport. (WB)

A characteristic of specificational clauses is that they are reversible, i.e. that they allow for a subject-complement switch (Huddleston and Pullum, 2002). In unmarked non-reversed specificationals, the value (in bold) is construed as complement, e.g. (3a); in reversed specificationals, by contrast, the value functions as subject, e.g. (3b).

(3) a. The President of the United States is Donald Trump. (The Independent)

b. Not Hilary Clinton, but Donald Trump is the President of the United States. ${ }^{3}$

The possibility to assign the functions of subject and complement in the reverse way is particularly clear when the value is expressed by a pronoun, which takes the oblique case in non-reversed clauses like him in (4a), but the nominative case like he in (4b).

(4) a. Paul Burrell says he's afraid of snakes, but I think the biggest snake in the "I'm a celebrity" jungle is him. (WB)

b. ... I think he is the biggest snake in the "I'm a celebrity" jungle.

The construal of the typically discourse-new value as subject preceding the pragmatically presupposed variable lends added prominence to the value, for instance to express contrastiveness between the actual value Donald Trump vs. competitor value Hilary Clinton in (3b).

An important criterion in recognising specificational clauses is their typical information structure. As reported by Gundel (1988), two dimensions of information structure can be distinguished: a relational and a referential one. The relational dimension is concerned with the clause-internal relation between the variable and the value, interpreted in terms of a contrast between presupposition and focus (e.g. Declerck, 1988; Lambrecht, 1994; Keizer, 1997). The variable being presupposed is to be taken for granted or at least treated as common ground (Stalnaker, 2002: 701). The value conversely is the focus of the sentence (Declerck, 1988: 12) and thus expresses the most important and salient information in the given communicative setting. By marking the value as focal, the speaker presents it as vital for the hearer to add to his/her pragmatic knowledge (Dik, 1997: 326), as with heterosexual intercourse in (5).

(5) The major route of transmission of HIV is heterosexual intercourse. (WB)

The value being focal is reflected by the fact that specificational clauses can be probed by interrogatives that explicitly enquire after the value, as in (5').

(5') What/which is the major route of transmission of HIV?

This is crucial, as well, for the interpretation of reversed clauses as specificational (Patten, 2012: 80). If, for instance, in (6), the most likely target were focal, the resulting interpretation would be of a predicational clause that gives a description of central London (cf. 'what is central London like?), rather than of a specificational clause that reveals what the most likely target of a terrorist attack in Britain is (cf. 'what would be the most likely target?').

\footnotetext{
${ }^{2}$ Our use of the terms 'variable' and 'value' is different from (Halliday, 1967b), where both the identified - e.g. the winner in (1) - and the identifier - e.g. Darryl Wakelin - in his 'equative' clauses can be variable or value. For him, the distinction hinges on two dimensions, firstly whether the identification is 'encoding' or 'decoding', and secondly whether the identifier specifies the function or form of the identified. In this paper, however, we focus solely on specificational clauses (a subtype of Halliday's equatives), so that the terms 'variable' and 'value' consistently refer to the identified and the identifier respectively (in line with other studies of specificational clauses, e.g. Declerck, 1988; den Dikken, 2006; Mikkelsen, 2005; Patten, 2016, 2012; Van Praet and Davidse, 2016).

${ }^{3}$ The example (3b) is made up, to illustrate as clearly as possible the difference between non-reversed (3a) and reversed (3b) specificational clauses.
} 
(6) If Britain were to face a terrorist attack, central London would be the most likely target. (WB)

The assumption in the literature is that the informational focus of the specificational sentences is marked intonationally, so that the value is the site of the nuclear (tonic) accent (Declerck, 1988: 13).

Mikkelsen (2005) argues that "part of what governs [the relational] topic-focus distribution in copular clauses [...] is 'discourse-familiarity', that is, the referential dimension of information structure (ib.: 135). The referential dimension pertains to the activation status of the referent, i.e. the extent to which the information presented by the speaker has already been evoked in the prior discourse and is presumed to be recoverable for the hearer (Prince, 1992; Birner, 1994). Mikkelsen (2005) proposes that specificational variables must be available to the hearer in the prior context (ib.: 134) and cannot be introduced de novo into the discourse ( $i b .:$ 152). This, however, somewhat blurs the distinction between the referential and the relational dimensions. Drawing on Prince's (1981) hierarchy of discourse-givenness (nicely visualised in Kaltenböck (2005), cf. Fig. 1), Patten (2012) provides a more fine-grained analysis that distinguishes between textually or situationally evoked, inferable and new (i.e. unused, brand-new unanchored or brand-new anchored) information.

Patten (2012: 52-52) claims, definite variables are either "explicitly evoked" in or "inferable from the discourse context", while indefinite ones are either "inferable" or "brand-new anchored", in the sense that the description they provide is not only freshly introduced to the discourse, but also explicitly related to a referent available from the discourse context. In (7), for instance, the definite variable the effect on Heathrow is inferable from the prior mention that rationalisation will be good for airports such as Heathrow; the value bigger planes, by contrast, is introduced as new information anchored to the prior context via the expected presence of planes in airports. In (8), the indefinite variable one thing that takes precedence introduces new information but in relation to previously expressed idea of 'buying a new plant': as such, it is new-anchored, rather than brand-new like its corresponding value scent.

(7) Rationalisation among airlines will be good for the core airports, such as Heathrow, Paris and Frankfurt. The effect on Heathrow is likely to be bigger planes as routes are shifted to Heathrow. (WB)

(8) When I am buying a new plant it must be easy to care for. But one thing that takes precedence is scent. (WB)

The information structure of an utterance in English is generally believed to be signalled by its intonation. In the 'British' tradition of prosodic analysis (e.g. Kingdon, 1958; O'Connor and Arnold, 1968; Halliday, 1967a, 1970; Crystal, 1969, 1975; etc.), utterances are divided in tone units (or 'tone groups', 'intonation groups', etc.). These are considered to coincide with one unit of information (Halliday, 1970: 3). The obligatory part of the tone unit (hereafter TU) is the nuclear or tonic accent which is the most prominent syllable that carries the TU's pitch movement, e.g. worry in (9).

\section{(9) ^`’m getting too old to !w $\backslash$ orry a_bout it\# (LLC)}

The nucleus is taken by Halliday (1970: 40) to mark the information that is both focal and the culmination of the information presented by the speaker as not being recoverable from the preceding discourse. Crystal (1969: 263) agrees that the placement of the nuclear accent signals the most informative point in the tone-unit but does not discuss it in terms of newness. Pierrehumbert and Hirschberg (1990) go further and argue that an $\mathrm{H}$ pitch accent marks a referent as new regardless of whether it is nuclear or pre-nuclear. Others such as Lambrecht (1994: 263) argue though that while newly introduced referents are accented, not all accented referents are necessarily newly introduced. However, he agrees with Halliday that nuclear accents signal newsworthiness Lambrecht (1994: 263)(ib.: 325). Ladd (2008) argues like Crystal that nuclear accents equate with information foci. Thus, while the informational status of pre-nuclear accents remains the subject of some dispute there is unanimity that nuclear accents project the focus of the tone group. Yet, at the same time, the more information an utterance adds to the discourse, the more TUs the utterance will be segmented into and, hence the more

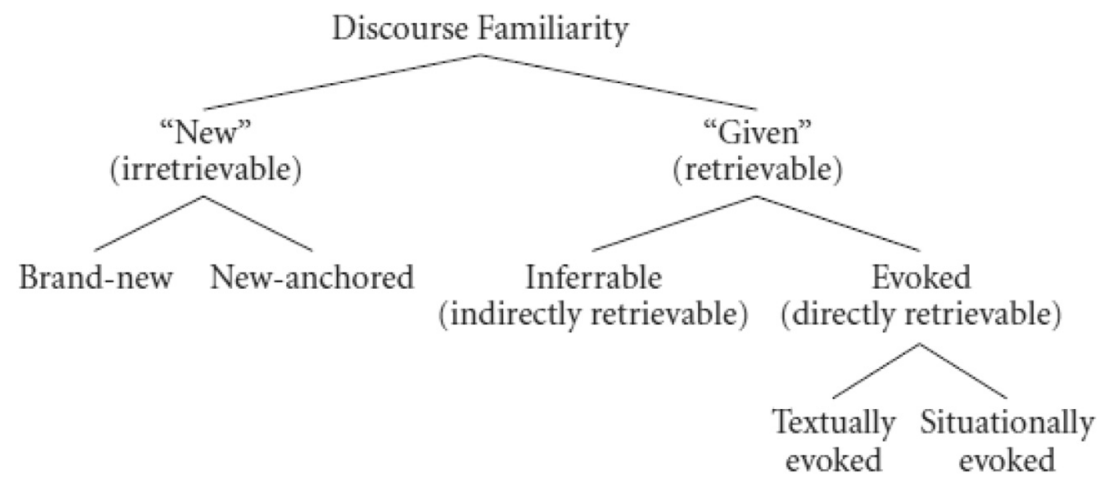

Fig. 1. A taxonomy of discourse-familiarity (Kaltenböck, 2005: 127). 
nuclear syllables there will be, as in (10) where one sentences is split up in three TUs (giving prominence to $s \backslash e e i n g, v / \backslash i v a$ and $W / \backslash$ ednesday).

(10) ^you`ll be $s \backslash$ eeing him\# at ${ }^{\wedge}[\mathrm{dhi}]$ at ${ }^{\wedge}[\mathrm{dhi}] . \mathrm{v} / \backslash$ iva\# . ${ }^{\wedge}$ on $\mathrm{W} / \backslash$ ednesday\# (LLC)

As such, both an utterance's tonality (i.e. the segmentation into TUs) and its tonicity (i.e. the placement of the nucleus within a TU) are interlinked in a speaker's strategy to present different pieces of information as salient or not. Importantly, new information, in the referential sense, is not restricted to the nuclear syllable and is frequently pre-nuclear. However, the nucleus signals the most prominent relational information within the TU.

Finally, the choice of tone - that is, the major pitch movement within the TU - also plays a role in the presentation of information. The function of tone is mainly communicative, in that it signals the information status accorded to the proposition expressed by the TU (Tench, 1996: 80). A basic contrast between falling and rising tones, as in (11) and (12), has been attributed a variety of different meanings, such as the expression of certainty vs. uncertainty (Halliday, 1970: 23); completeness vs. incompleteness (or continuation) (Tench, 1996: 80); definiteness or dominance vs. noncommitment or deference (Cruttenden, 1997: 177; Tench, 1996); telling or not telling (Brazil, 1997; Gussenhoven, 2004; O'Grady, 2010), etc.

(11) well I`m quite "^c $\backslash$ ertain that they_do\# (LLC)

(12) it`s $\wedge$ for five p/ounds\#.r/ight\# (LLC)

Furthermore, rise-falls, semantically grouped together with falls, express finality, definiteness, etc., but also convey additional 'impressed' or 'challenging' meanings (Cruttenden, 1997: 92-93), as in (13).

(13) ^that`s for the:b/ \ank\# not the tr/ \ain\# (LLC)

Fall-rises are considered by some as variants of rising tones (e.g. Brazil, 1997; Cruttenden, 1997), but by others as independent tones which signal a variety of meanings. For instance they function to (i) give 'major prominence' to a piece of information (Sharp, 1953), (ii) to connect a discourse entity to others (Hirschberg and Ward, 1985), which Ladd (1980) describes as 'focus within a set', (iii) to signal a reservation (Halliday, 1967a; Halliday and Greaves, 2008) or (iv) present information as "the speaker's personal opinion offered for consideration" (Tench, 1988: 172), as illustrated in the sequence of fall-rises in (14).

(14) ^one of the:things that oc:curs to:m\/e\# is _[dhi:] [@:m] !student:n \/urses\# at"^tending ":family "!s $\backslash /$ essions\# in [dhi] - !hospital that they`re _actually ! tr \/aining 'in\# (LLC)

Finally, the rather less frequent level tone functions to present a particular piece of information as obvious if not selfevident or to indicate that the speaker is not engaging communicatively (Brazil, 1997; Tench, 2003), e.g. (15).

(15) $\quad \mathrm{y}=\mathrm{es}^{\mathrm{a}}$ of $\mathrm{c}=$ ourse\# (LLC)

In this paper we home in on the prosodic realisation of specificational clauses, both in their default non-reversed and their marked reversed order. The aim is to study the interaction between intonation and information structure, whereby different choices of tone, tonicity and tonality are predicted to express different ways of packaging and presenting the information conveyed by the specificational utterance. The question we address is twofold: a first concern is the intonational coding of the specificational variable's relation to the prior discourse, notably its presentation as presupposed or not. The second topic of interest is the variable's relation to the following discourse, viz. to the value that it introduces. In doing so, this paper provides a speech functional analysis of the prosodic construal of the specificational variable and its interaction with the variable's referential and/or relational information status.

\section{Method}

This paper aims to provide a descriptive qualitative analysis of the intonation structure of specificational copular clauses, both in their non-reversed and reversed order, with the value construed as complement or subject respectively. In the analysis, both specificational clauses with a definite and an indefinite variable were included. The data were taken from the London-Lund Corpus of Spoken English (henceforth, LLC). The LLC consists mostly of conversations between educated speakers from London, recorded between 1953 and 1987. The data includes both sound files and their transcriptions, 
prosodically annotated ${ }^{4}$ by the compilers in the British 'nuclear tone approach' (e.g. Crystal, 1969). The entire corpus adds up to 500,000 words, including 100 texts that each consist of 5000 words. The utterances are divided into TUs, i.e. the basic domain of the pitch movement, the boundaries of which are indicated by the symbol \#, as in (16).

(16) well my ! $\backslash \backslash$ ague am'bition\# is to get ${ }^{\wedge} \mathrm{y} \backslash$ es\# is to get an ad:ministrative 'post $\mathrm{h} \backslash$ ere\# (LLC)

The most prominent manifestation of the pitch movement is the nucleus or tonic syllable, on which the relevant tone is marked (e.g. $v \backslash$ ague in [16]). Based on the different direction of the pitch movement, the English tone system distinguishes three 'simple' tones, viz. falls ' ', rises '" and level '-' tones. Two additional 'complex' tones can be derived from the former two, namely fall-rise ' $\mathrm{V}$ ' and rise-fall ' $\mathrm{N}$ '.

(i) fall: \, e.g. the only shift of contact is th $\backslash$ ere\#

(ii) rise: /, e.g. is this a spare p/aper\#

(iii) level or low rise: - or $=$, e.g. oh to hell with th=is\#

(iv) fall-rise: $\vee$, e.g. I think he's a $s \backslash$ /erious candidate\#

(v) rise-fall: $\Lambda$, e.g. well he's such a d/\ynamo\#

In addition, the LLC also recognises 'compound' tones, which are essentially "simple tones and complex tones in various combinations (e.g. fall + rise, rise-fall + rise)" (Halliday and Greaves, 2008). Contrary to complex tones, compound tones are considered binuclear, having a sequence of two accents - a primary accent followed by a secondary one - within one TU.

(vi) fall + rise, e.g. that's a good $p \backslash$ oint of yours R/eith\#

The theoretical grounds for acknowledging compound tones are, however, shaky, though see Ladd (2008). Halliday's (1970: 12) initial argument was based on the notion of 'fusion', or the idea that the two tones have become fused in a single tone group, with no possibility of introducing a further intonational prominence between the two. Watt (1992): 153) though found very little instrumental evidence for the existence of compound tones. Furthermore, TU boundaries are sometimes difficult to identify (Barth-Weingarten, 2016), particularly when deciding between a compound tone and a sequence of two separate TUs. Cruttenden (1997): 36) amongst others argues that is more sensible in such cases to consider syntactic or semantic factors and regard so called compound tones as sequences of two independent TUs. Tench (1996) and O'Grady (2017) both note that as TUs correspond with information units it is inelegant to talk about primary and secondary TUs. Accordingly, for the purpose of this paper we consider compound tones as involving a sequence of two separate TUs, so that (vi) is transcribed as (vi'):

(vi') that's a good $\mathrm{p} \backslash$ oint of yours\# R/eith\#

Our own dataset was manually collected from the LLC and comprises a total of 240 examples. The data were gathered by first annotating all specificational examples in the transcriptions, from which we then took a random sample of 250 examples. For each of the 250 examples, we subsequently looked up the original spoken version in the audiofiles: 10 examples were not sufficiently understandable and therefore taken out of the dataset. The resulting dataset of 240 examples includes 198 nonreversed and 42 reversed specificational clauses. Of the non-reversed specificationals, 125 had a definite variable and 73 an indefinite one. Their reversed variants counted 29 definite variables and 13 indefinite ones (cf. Table 1).

The data in our own subcorpus were divided into two main groups. One group contains the data in which the variable and value were realised within the same $\mathrm{TU}$ (hence, having only one nuclear accent), as in (17); the other comprises the examples in which both the variable and the value carried a (series of) nuclear tone(s), as in (18).

(17) I only have:two other:w $\backslash$ omen\# on $\mathrm{m} \backslash \mathrm{y}$ [li] 'list\# and one is Mar:ian von ":C $\backslash$ /olditz\# and the other is ! Joan "! $\backslash$ ackson\# (LLC)

(18) my [t] my $\mathrm{t} \backslash$ utor\# at:Tr $\backslash$ inity\# was a man called !Theobald !BI $\backslash$ acklane\# (LLC)

The first group was then analysed for the placement of the nucleus (cf. tonicity) and the direction of the pitch change (cf. tone), so as to determine the prominence-pattern of the clause and the way its information is presented to the hearer respectively. The data in the second group were examined for the number of TUs over which both variable and value were respectively spread (cf. tonality): the clause's tonality indicates how many pieces of information the speaker marks as individual units, each with its own salient information, e.g. one TU for each of the two specificational clauses in (17) and three

\footnotetext{
${ }^{4}$ The more precise prosodic marking in LLC includes the following symbols (as described in Kimps et al. (2014: 67)):^silent onset; . brief pause; - unit pause of one stress unit; ' normal stress; " heavy stress;: higher pitch level than preceding syllable; ! booster higher than preceding pitch prominent syllable; [] partial words or phonetic symbols; \{\} subordinate tone unit; * simultaneous talk; (()) incomprehensible words; VAR various speakers.
} 
Table 1

The distribution of (non-)reversed and (in)definite specificational clauses in the dataset.

\begin{tabular}{|c|c|c|c|c|}
\hline Non-reversed & 198 & $\begin{array}{l}\text { Definite } \\
\text { Indefinite }\end{array}$ & $\begin{array}{l}125 \\
73\end{array}$ & $\begin{array}{l}\text { the hardest thing is to get } \backslash \text { in\# } \\
\text { one 'problem is leading qu } \backslash \text { estions\# }\end{array}$ \\
\hline Reversed & 42 & $\begin{array}{l}\text { definite } \\
\text { Indefinite }\end{array}$ & $\begin{array}{l}29 \\
13\end{array}$ & $\begin{array}{l}\text { th } \backslash a t \text { 's the idea\# } \\
\text { th } \backslash \text { at\# might be \one explanation\# }\end{array}$ \\
\hline
\end{tabular}

TUs in (18). Since the focus of this paper is the specificational variable's relation to the preceding and following context, we homed in on the construal of the variable NP, looking at its tone (or sequence of tones), its tonicity and its tonality. This allows us to examine the hypothesis in the literature that the specificational clauses' pragmatic presupposition is reflected in its intonation structure. In cases that do not fit the hypothesis, we consider why the specificational variable is given prominence (cf. tonality, tonicity) and how the information it conveys is presented to the hearer (cf. tone).

\section{Results}

The intonation structure of specificational clauses was found to vary considerably, not only between non-reversed and reversed specificationals but also among these respective constructions types themselves.

Firstly, non-reversed and reversed specificationals differ considerably in terms of tonality, that is, the number of TUs over which they tend to spread $\left(X^{2}(1)=59.189, p<.001\right.$; Cramer's V: 0.509) (Table 2).

Table 2

The tonality of non-reversed vs. reversed specificational clauses.

\begin{tabular}{lll}
\hline & One TU or less & More than one TU \\
\hline Non-reversed & $33(17 \%)$ & $165(83 \%)$ \\
Reversed & $32(76 \%)$ & $10(24 \%)$ \\
\hline
\end{tabular}

Among non-reversed specificationals, the choice for a definite or indefinite variable does not affect the tonality of the constructions as a whole: 100 of the 125 definite clauses and 65 of the 75 indefinite ones spread over more than one TU, that is, $80 \%$ and $87 \%$ respectively, as in (19) and (20). Hence, no significant difference between definite and indefinite non-reversed clauses was found $\left(X^{2}(1)=1.0182, p=0.313\right)$.

(19) the ^best 'way to 'get a j/ob\# is not to 'care _whether you _g \et it or 'not\# (LLC)

(20) ^one of the:pr \oblems\# that Scotland ! has !f $\backslash$ aced\# for 'many:y \/ears\# . is a lack of de:c \/ision 'making\# a drift 'of this de:cision 'making p/ower\# towards the !c \entre\# (LLC)

In longer specificational sentences, the tonality of the variable itself, however, did vary significantly between its definite and indefinite construal: variables longer than one TU were much more common when indefinite (i.e. 31 examples or $48 \%$, as in [19]) than when they were definite (i.e. 14 instances or $14 \%)\left(X^{2}(1)=19.31, p<.001\right.$; Cramer's V: 0.357) (Table 3).

Table 3

The tonality of (in)definite variables in specificational sentences longer than one TU.

\begin{tabular}{lll}
\hline & one TU or less & more than one TU \\
\hline definite variables & $86(86 \%)$ & $14(14 \%)$ \\
indefinite variables & $33(52 \%)$ & $30(48 \%)$ \\
\hline
\end{tabular}

The varying lengths of definite vs. indefinite variables (when subject) are accounted for by the variation of their discourse statuses ( $p=0.003$, as determined by a Fisher's Exact Test; Cramer's V: 0.249) (cf. Table 4). While both definite and indefinite variables are most likely to be 'new-anchored', a much higher proportion of the former were found to be inferable or given as well (together $47 \%$, compared to $35 \%$ with indefinite variables). The lower degree of communicative dynamism of inferable or given information - that is, the extent to which they add to the shared knowledge of speaker and hearer - would appear to allow for a more concise packaging of information, resulting in a smaller amount of intonation/ information units.

The fact that non-reversed specificationals tend to spread over more than one TU problematises the oversimplified assumption that the specificational value is the focal accent of the specificational clauses (Declerck, 1988: 13). While it is true that short non-reversed specificationals consistently placed the nuclear accent on the value (thus giving it intonational prominence) (as in [21]), the picture is more complicated with longer specificationals, e.g. (22). 
(21) the only 'subject I 'wanted to 'do was:Fr $\backslash$ ench\# (LLC)

(22) the very "!f \ irst _person I_met\# before ! $\backslash /$ unch\# was [dhi] - - !h \istory _don\# (LLC)

Table 4

The variation in discourse status between definite vs. indefinite variables (when subject).

\begin{tabular}{lll}
\hline & Definite variables & Indefinite variables \\
\hline Brand-new & $5(4 \%)$ & $5(7 \%)$ \\
New-anchored & $61(49 \%)$ & $42(58 \%)$ \\
Inferable & $31(25 \%)$ & $4(5 \%)$ \\
Given (textually/situationally) & $28(22 \%)$ & $22(30 \%)$ \\
\hline
\end{tabular}

In the latter case, the variable and value are segmented into separate TUs, each with their own tonicity and, hence, internal prominence-marking. In such longer sentences, the variable's intonation pattern - and, notably, its choice of tone - can, however, serve another interpersonal function, namely by reflecting the speaker's interpretation of the information within the ongoing discourse, that is, in relation to the prior and the following context. As the variable introduces the value, its tone or pitch contour can thus announce how the information conveyed by the value is to be interpreted vis-à-vis the discourse context.

In our data, we found, for instance, that a notable distinction can be observed between definite and indefinite variables' choice of tone (if uttered on a separate $\mathrm{TU}$ ). While definite variables showed no particular preference for either falling tones (51\%) or rising tones (49\%), indefinite ones strongly favoured rising tones (i.e. in 47 of the 63 indefinite examples, or $75 \%$ ) $\left(X^{2}(1)=9.4349, p=0.002\right.$; Cramer's V: 0.253).

(23) their $\mathrm{j} \backslash$ ob 'is\# to think the:ways of:doing the $\mathrm{b} \backslash / \mathrm{est} \#$ for each 'child as an:indiv $\backslash$ idual\# (LLC)

(24) one of the con:ditions of my:taking the:j \/ob with 'Frank 'Morgan\# was that I . re:m \ained\# a ^ Ph'D 'student 'under 'Peter !K $\backslash$ ennedy\# (LLC)

On a more specific level, definite variables were most likely to end in a fall (49\%) as on $j \backslash o b$ in (23); whereas indefinite variables favoured fall-rises (41\%), as on $j \backslash / o b$ in (24) (cf. Table 5). Hence, the difference in specific tones was significant as well $\left(X^{2}(2)=9.9076, p=0.007 \text {; Cramer's V: } 0.251\right)^{5}$.

Table 5

The variation of final tones in definite vs. indefinite variables.

\begin{tabular}{lllll}
\hline & Falling tone & & \multicolumn{2}{l}{ Rising tone } \\
\cline { 2 - 5 } \cline { 3 - 5 } & Fall & Rise-fall & Rise & Fall-rise \\
\hline Definite variables & $49(49 \%)$ & $2(2 \%)$ & $25(25 \%)$ & $23(23 \%)$ \\
Indefinite variables & $16(25 \%)$ & 0 & $18(29 \%)$ & $26(41 \%)$ \\
\hline
\end{tabular}

Reversed specificationals, on the flip side, tend to be generally shorter than their non-reversed counterparts, as in (25) where the value charisma is subject.

(25) charisma is the:word I was $1 \backslash$ ooking for\# (LLC)

No significant difference in tonality was found between definite and indefinite reversed clauses, with both being typically one TU or less ( $p=0.6966$, as determined by a Fisher's Exact Test). Part of the reason for reversed clauses being generally shorter than non-reversed ones - and, hence, packing less information - has to do with the discourse-embedding of both the variable and, more importantly, the value. We will argue that, in reversed clauses, the construal of the value as subject, linearly preceding the variable, foregrounds the former's relation to the discourse context. An important factor is the discourse-familiarity of the value and variable (Birner, 1994). In our data, we found that the discourse-status of both arguments does indeed influence the order in which the specificational clause is construed (Table 6). Two Fisher's Exact Tests one for the variable's discourse status in non-reversed vs. reversed clauses $(p=0.003)$ and another for the value's $(p<.001)-$ showed the correlation between discourse status and the (non-)reversed construal to be significant. The respective effect sizes of the correlations suggest, however, that the effect of the value's discourse status is greater (i.e. Cramer's V: 0.478 ) than the variable's (i.e. Cramer's V $=0.246$ ). As Table 6 shows, the value is most likely to be 'brand-new' or 'new-anchored' in nonreversed clauses, but typically 'textually or situationally given' in the reversed ones.

A large proportion of the textually or situationally given values is accounted for by the highly frequent use of the demonstrative pronoun as subject/value in reversed specificational clauses, e.g. (26). We found that 19 out of the 29 definite

\footnotetext{
${ }^{5}$ The chi-square test for the variation of specific tones did not include rise-falls or level tones, which were not sufficiently frequent to allow for a reliable statistical analysis.
} 
Table 6

The discourse status of the variable and value in non-reversed vs. reversed clauses.

\begin{tabular}{|c|c|c|c|c|}
\hline & \multicolumn{2}{|l|}{ Variable } & \multicolumn{2}{|l|}{ Value } \\
\hline & Non-reversed & Reversed & Non-reversed & Reversed \\
\hline Brand-new & $10(5 \%)$ & $1(2 \%)$ & $73(37 \%)$ & $7(17 \%)$ \\
\hline New-anchored & $103(52 \%)$ & $12(29 \%)$ & $84(42 \%)$ & $9(21 \%)$ \\
\hline Inferable & $35(18 \%)$ & $18(43 \%)$ & $18(9 \%)$ & 0 \\
\hline Given (text./situation.) & $50(25 \%)$ & $11(26 \%)$ & $23(12 \%)$ & $26(62 \%)$ \\
\hline
\end{tabular}

reversed specificational clauses (66\%) and 9 out of the 13 indefinite ones (69\%) had demonstrative subjects which often occurred in thematic (clause-initial) position and did not carry the information focus, thus corroborating (Halliday, 1967b: 231 ) earlier observations. Indeed, 21 (72\%) of our definite reversed examples and 10 (77\%) of our indefinite examples had nuclear accents on the variable rather than the value, as in both (25) above and (26) below. As a result, the commonly accepted criterion that specificational clauses have either (i) unmarked information structure with the value as complement containing the focus or (ii) marked information structure with the focal value falling on the subject is not supported.

(26) but "^h $\backslash$ unting\# de^ $\backslash \backslash$ iberately\# in^volves !cr/uelty\# and in ${ }^{\wedge}$ fact 'that is the 'whole 'purpose be! $\backslash$ ind it\# what ${ }^{\wedge}$ ever you may ! $\backslash \backslash$ ay\# (LLC)

To sum up, the quantitative analysis outlined in this section raises compelling differences in the prosodic realisation of non-reversed and reversed specificational clauses, construed either with a definite or indefinite variable. In the following Section 4, we take up an in-depth qualitative analysis of those constructional differences, focusing in particular on their interpersonal and textual function.

\section{Discussion}

This section examines how speaker's intonational choices present the information conveyed by specificational clauses. It focuses both on the segmentation of information in sequences of TUs and the TU internal prominence-marking. In Section 4.1 we home in on short non-reversed clauses, consisting of one TU, in which the accenting or de-accenting signals differences in salience between the variable and value. Longer specificational clauses, in which the variable and value are uttered in different TUs, mark both constituents as noteworthy. In Section 4.2 we outline various reasons why variables, despite their hypothesised pragmatically presupposed status, receive prominence. In our discussion we distinguish between specificational clauses where the variable ends in a rising tone (Section 4.2.1) and those which end in a falling tone (4.2.2). Finally, in section 4.3 we consider reversed specificational clauses - where the value functions as subject - and investigate the assumption that within specificational clauses the focus is on the value (Declerck, 1988; Mikkelsen, 2005).

\subsection{Short non-reversed specificational clauses}

The most straightforward specificational clauses to interpret in terms of information structure are the ones realised in one TU. On the assumption that the TU represents a single information unit (Halliday, 1970: 3), the packing together of the variable and value implies that their combined ideational content forms one manageable piece of information (Tench, 1988: 21-22). The information that the specificational clause adds to the ongoing discourse can be processed as having one point of focal information signalled by the placement of the nuclear prominence (Crystal, 1969: 263). While the decision to accent certain words and de-accent others reflects the relative importance or salience of the rest of the information in the TU (cf. Pierrehumbert and Hirschberg, 1990: 286), it is the nuclear accent that indicates the focus of information (Halliday, 1970: 4). In non-reversed specificational clauses of one TU, this information is typically the value, as in (27).

(27) so 'far* we`ve:only got "! two other n/ames\# and [@:] !one is H/ocking\# and the other`s !H \erman\# (LLC)

In (27) the variables in the two consecutive specificational clauses, viz. one and the other, are both evoked in the prior context via the mention of two other names. As such, they are informationally given and, hence, intonationally backgrounded in favour of their corresponding values, on which the nuclear tones are realised. Notice, in addition, that the first indefinite variable one is realised with a pre-nuclear accent $\left(\mathrm{H}^{*}\right)$ giving it pre-tonic prominence (cf. Fig. 2). This is despite its existence being inferable from the prior context and provides support for Lambrecht's (1994) view that not all accented referents are new. The shift from 'two other names' to 'one' in particular is marked by a step up in pitch. By contrast, as a result of the first specificational clause, the second act of specification is expected, so that the variable the other is predictable from the prior context and, therefore, presented as less noteworthy as reflected by its lower pitch signalling it las relatively less prominent.

Both specificational clauses in (27) are short and, hence, contain relatively limited information. But also longer specificational clauses can be compressed into one TU, where the decision to mark the variable as less prominent is signalled more, for instance by the increased speed with which the variable the only thing you want to do is uttered in (28). 


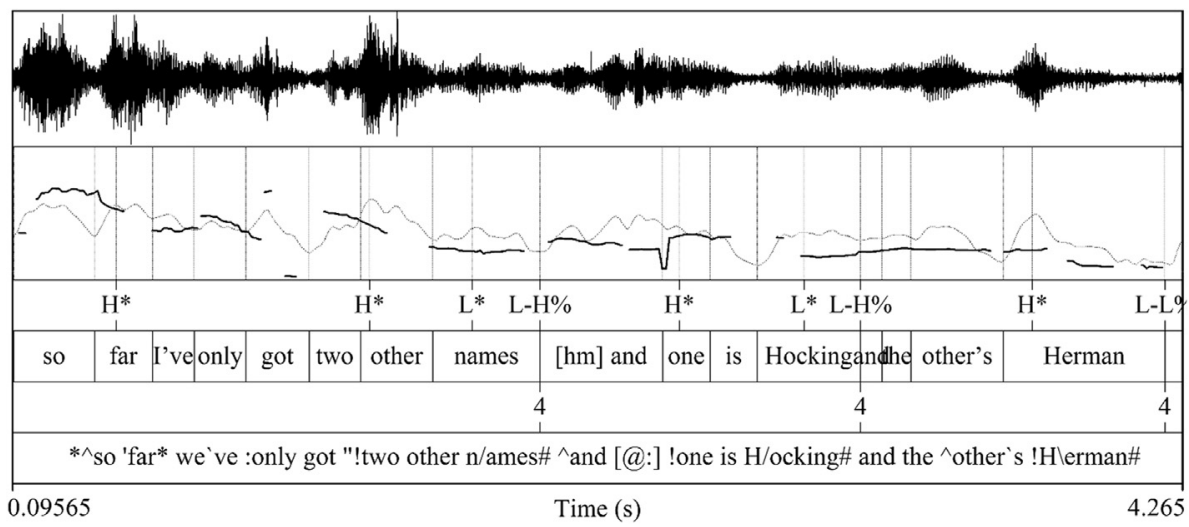

Fig. 2. Waveform and F0 contour for example (27).

Even though the variable in (28) is neither mentioned nor inferable from the prior context, where speaker and hearer discuss differences between university campuses in cities and small towns, the speaker still chooses to present the variable as presupposed. It is non-salient, in contrast with the value, in which the word away carries the nuclear tone (cf. Fig. 3). The fallrising tone on away signals a contrastive relation between the wish to get away and the inability to do so - as expressed in the following TU (Ladd, 2008).

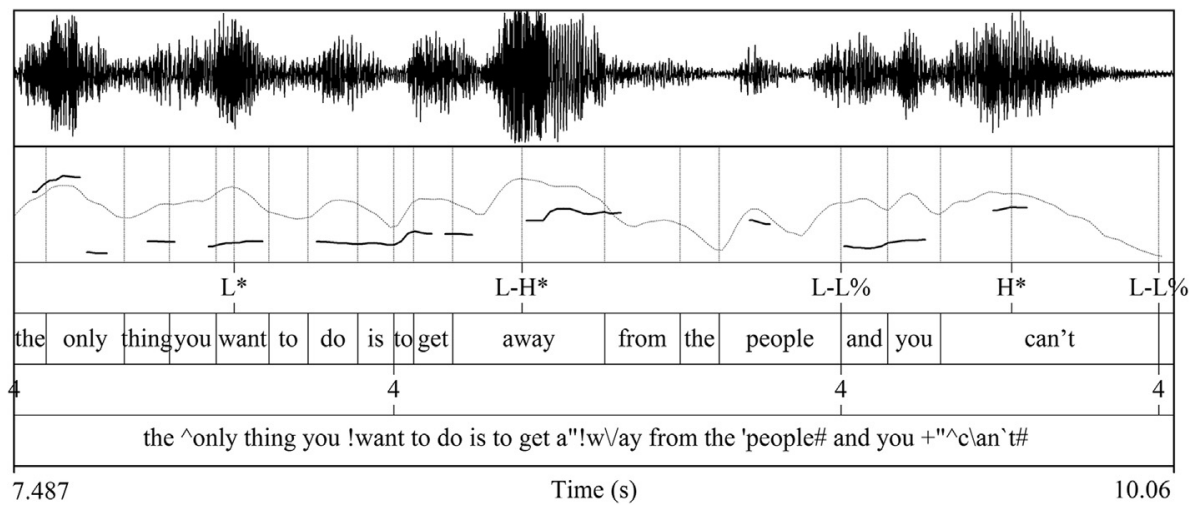

Fig. 3. Waveform and F0 contour for example (28).

\subsection{Longer non-reversed specificational clauses}

The assumed dichotomy between presupposition and focus, (cf. Lambrecht, 1994), is less clear - if tenable at all - in cases where the variable and the value are realised in separate TUs. Each of which carries nuclear tone. The sequential segmentation of variable and value in separate TUs presents them as individual chunks of information (Halliday, 1967a, 1970; Tench, 1988). In this section we look at the reasons for presenting the variable as an individual chunk of information or a series of chunks and how it affects the interpersonal meaning of the specificational clause. In addition, we will provide an in-depth descriptive analysis of the implications that the choice of nuclear tone has on the interpretation of the variable-value relation. We will show, notably, that the different pragmatic meanings associated with the definite vs. indefinite variable, i.e. as expressing (non-)uniqueness, bring about different preferences for rising vs. falling tones. We will relate this to their different interpersonal meaning potential.

\subsubsection{Variables ending in rising tones}

In our data, many specificational variables were realised with a rising tone (i.e. a rise, fall-rise or level-rise) on the nucleus or, in the case of variables longer than one TU, with a rising tone as the last nuclear tone of the variable (i.e. in 96 examples or $59 \%$ of the 163 'longer' specificationals). Interestingly, definite variables were generally balanced as to the ratio of falling and 
rising tones (resp. 51\% and 49\%). Indefinite variables, however, showed a pronounced preference for rising tones (75\%). In this section we will set out interpersonal meanings associated with rising tone and, in doing so, explain why the indefinite variable and its pragmatic function are particularly conducive to these rising tones.

A typical meaning associated with rising tones, particularly rises, is that they indicate non-finality, incompleteness or a look forward (Bolinger, 1989; Pierrehumbert and Hirschberg, 1990; Cruttenden, 1997; etc.). In non-reversed specificational clauses, continuation rises are particularly frequent in both definite and indefinite variables, which occur in non-sentencefinal position, e.g. (29).

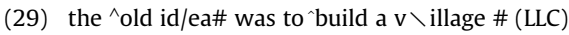

In the context leading up to (29) the speaker and hearer are discussing Croydon Council's plan to evict tenants with joint incomes amounting to over twenty pounds a week. This, the speaker argues, will lead to segregation. The variable the old idea is introduced as new information. At the same time, it is anchored to the immediately prior co-text - the modern conception of segregating the poor from the reasonably well-to-do. By virtue of being 'new-anchored' (Prince, 1981), the variable is realised in a separate TU. Therefore the realisation of a nuclear accent on part of the variable gives it prominence and presents it as relatively 'newsworthy'. The fall on the value can be interpreted as 'complementary' to the variable's rising tone (Fox, 1986). It expresses a sense of completion, borne out by the following pause.

In addition to signalling continuation, the speaker may choose to use a rising tone to express her/his reservation or uncertainty towards the claim s/he is making. In (30), for instance, the speaker is advising the hearer on the latter's marital problems and on the option of marriage counselling.

(30) ${ }^{\wedge} \mathrm{w} / \mathrm{ell} \# \mathrm{I}{ }^{\wedge}$ think it 'may 'well $\mathrm{b} \backslash \mathrm{e} \#$ that $-^{\wedge}$ one of the $\operatorname{pr} \backslash /$ oblems\# ${ }^{\wedge}$ in your $\mathrm{m} \backslash /$ arriage\# ${ }^{\wedge}$ is that the 'things ! $\backslash \backslash$ ou have $\mathrm{f} /$ aith in\# $\wedge^{\wedge}$ she !! $\backslash \backslash$ oesn`t have f/aith in\# - and the ^things that !sh $\backslash e$ has 'faith in\# ${ }^{\wedge} \mathrm{y} \backslash$ ou don`t have ${ }^{*}$ faith in\# (LLC)

Not being a psychologist - let alone a marriage counsellor - the speaker employs a number of strategies to hedge the sensitive topic. First, the speaker initiates his turn with the downtoning I think it may well be that... Secondly, the indefiniteness of the variable (cf. one of the problems in your marriage) presents the specification as non-exhaustive. The exclusiveness of the indefinite variable is used to express the speaker's tentativeness towards the variable-value relation. Such tentativity is compounded by the sequence of fall-rises on the variable's two TUs, signalling that the specificational utterance represents a personal opinion (Tench, 1988: 20). The speaker invites the hearer to confirm or reject his suggestion, ${ }^{6}$ by emphasising the subjectivity of the statement.

The tentativity expressed by the falling-rising tone explains why it is particularly common with indefinite specificational variables, given the exclusiveness (i.e. non-uniqueness) implicature associated with indefinite specification (Declerck, 1988). The specified value is presented as a value or instance which could potentially satisfy the variable. Within certain contexts, the possibility of multiple instantiation can lead to a reduction in or lack of epistemic commitment to the act of specification. The speaker leaves open the option of other and perhaps more fitting values for the variable.

Another related meaning of the fall-rise is that it connects a discourse entity with other entities in the discourse (Hirschberg and Ward, 1985: 449). Ladd (1980) describes this as 'focus within a set', as expressed in (31).

(31) ^ $\backslash$ /one of the 'things that \# ${ }^{\wedge}$ one of the:m $\backslash /$ any 'things the 'books brings _out \{very ${ }^{\wedge} \mathrm{cl} \backslash /$ early 'is that\# $\}_{\#}$ they ${ }^{\wedge} \mathrm{W} \backslash$ ere de'cisively de'feated\# ${ }^{\wedge}$ in the "If $\backslash$ ield\# $-^{\wedge} \mathbf{b} \backslash / y$ the _Allied_armies\# (LLC)

Example (31) starts off with a falling-rising tone on the indefinite pronoun one, thus emphasising its exclusiveness whereby the speaker shifts the focus towards a single instance of a set, the size of which is left unspecified. The restart - i.e. one of the: $m \backslash$ /any 'things... - deaccents the indefinite pronoun to give prominence to many, thus explicating and underscoring the possibility of multiple instantiation by giving a description of the magnitude of the reference set from which the instance under discussion is drawn. Since definite variables have an inclusiveness (or uniqueness) implicature, fall-rises are used relatively less frequently. In fact, fall-rises occurring in definite variables function to bring out the information based on which the instance under discussion can be distinguished from rather than associated with.

Finally, though relatively rare, the variable may also be realised with (a series of) level-rises, as in (32) (the only example we found of this pattern).

(32) the ^basic:tr $=$ uth\# $\mathrm{a}^{\wedge}$ bout $! \mathrm{m}=$ en\# . is that ${ }^{\wedge} \mathrm{men}$. 'like to 'be with 'other:m $\backslash$ en\# (LLC)

\footnotetext{
${ }^{6}$ The pronouns referring to the speaker or hearer reflect their actual gender.
} 
Halliday (1970) points out that the sequence of level tones followed by a falling TU does not merely link two or more pieces of information but signals an obvious if not self-evident connection between them. The speaker, a woman, presents her belief as an objective 'basic truth' to be taken for granted. This serves as a solid argument against mixed colleges (i.e. the topic of discussion). The speaker does not invite her hearer, also a woman, to agree or disagree. But neither does she underscore her own (lack of) authority on the matter. Interestingly, later on in the discourse, when the speaker is not present, the hearer comments on the statement, explicitly saying she did not agree with it herself but felt "it wouldn't have been very tactful to argue" with "this sort of rationalisation".

In sum, variables ending in rising tones can have a number of different interpersonal functions, the most common one being to signal continuation. A rising tone may also be used to signal the speaker's reluctance to commit to the variable-value correspondence or to emphasise the subjectivity of the specificational clause. Indefinite variables, and their implication of non-exhaustive specification, were found to be particularly conducive to the expression of tentativity. Specifically the meaning potential of fall-rises of focusing on one entity within a set was found to be remarkably common with indefinite variables and implied non-contrastive comparison between the actually specified and competitor values.

\subsubsection{Variables ending in falling tones}

Interestingly, despite typically signalling finality or completion, the use of a falling tone on the variable (or as the last nuclear accent of the variable) was, in our data, about as common as rising tones, at least when the variable was definite (cf. $51 \%$ falling tones), e.g. (33).

(33) I said if ${ }^{\wedge}$ you make a statistical an:alysis of the "!overs $/ \backslash$ eas $\left\{{ }^{\wedge} \mathrm{c} \backslash\right.$ andidates\# $\}$ - the ${ }^{\wedge}$ candidates who ! $\backslash$ ass\# . are ${ }^{\wedge}$ those candidates who are:getting:thirteen:fourteen !ffifteen $\mathrm{m} \backslash$ arks\# . on ${ }^{\wedge}$ those . ! two qu $=$ estions\# and ((that $`$ s)) ${ }^{\wedge}$ usually the clause an: $\backslash$ alysis _question\# (LLC)

In (33) the speaker and hearer are discussing which essay questions count most in deciding whether university applicants pass an entrance examination. The clause preceding the specificational clause narrows down the discussion from candidates in general to the overseas ones in particular. The rise-fall on overseas indicates that the new content moves beyond the existing content, that is, expands the shared knowledge (Knowles, 1984: 235). In relation to the overseas candidates, the specificational variable subsequently demarcates the candidates who pass as a subset of the former. The intonational and informational focus is on pass, which as part of the restrictive relative clause functions not only to identify the relevant subset but also to contrast them with the failed candidates, as conveyed by the extra emphasis that the raised pitch on pass adds. The value, spread over two TUs, adds two main pieces of information, namely (i) the 'marks' candidates get and (ii) the questions that weigh most in the grand total. Finally, by realising the variable with a falling tone, the speaker expresses his certainty and authority. He asserts that the value he specifies is the one corresponding to the variable and that he is certain of the truth of his assertion.

The expression of certainty and assertiveness is particularly clear in (34), where the variable is realised as a series of three TUs, each produced with a fall.

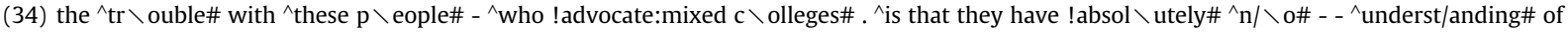
the $\wedge$ $n \backslash$ eeds $\}$ of: $m \backslash$ en\#

The choice to set apart the trouble as a single TU and, hence, a separate information unit reflects the speaker's insistence that there is in fact a problem both with mixed colleges and their advocates. The pauses after the second and third TU add a sense of resoluteness to the utterance, leaving time to let the information sink in. Likewise, in the value, the compartmentalisation of the information into many small TUs gives prominence to the individual pieces of information, as if to hammer each of them in (i.e. absolutely - no - understanding - needs - men). The use of a rise-fall on no further adds to its prominence by signalling not only a sense of definiteness but also increased emotional involvement (Cruttenden, 1997). This implicitly signals the speaker's view of the opinions of those advocating for mixed colleges.

Much less frequent is the use of a rising-falling tone on the variable itself, which only occurred in two cases of all nonreversed specificationals, both of which were examples of definite specificationals, e.g. (35).

(35) *but ${ }^{\wedge} \mathrm{Mr} \mathrm{Nab} / \backslash$ arro\#* we "^know that you be:I/ \ieve_this\# . the ${ }^{\wedge} \operatorname{str} / \backslash$ ange _fact_is\# that you ${ }^{\wedge}$ still haven't given us a !r $\backslash$ eason _for it\# (LLC)

In (35) the speaker presents Mr Nabarro's previously mentioned argument as a mere 'belief, the content of which is challenged, as expressed by the rising-falling tone. The variable the strange fact consequently marks a contrast with this belief, both prosodically by means of the rise-fall on strange and lexically by means of the opposition between 'fact' and 'belief. While not explicitly contradicting Mr Nabarro, the speaker in (35) points out the incongruity of Mr Nabarro presenting an apparently logical argument in the absence of any overt evidence. In that sense, the rise-fall on strange adds a touch of sarcasm (Cruttenden, 1997): the contextually relevant interpretation of the specificational clause is not that the speaker actually finds Mr Nabarro's failure to produce evidence strange, but rather that he believes the latter's argument to be false. 
To conclude, falling tones, unlike rising tones, express certainty or definiteness on the part of the speaker. This is particularly so in the case of the rather infrequent rise-falls. Their meaning potential includes speaker challenge of others' previous statements or implied assumptions. As such, falling tones are typically used to assert the speaker's authority. We argue this is because they are more likely to occur with definite variables where the unique one-on-one correspondence between the value and the variable typically warrants a higher degree of speaker certainty and assertiveness.

\subsection{Reversed specificational clauses}

As set out in Section 3, reversed clauses, often construed on one TU, tend to be generally shorter than non-reversed ones. This, we showed, is partly to do with the discourse status of the value. Non-reversed sentences are more likely to have either 'brand-new' or 'new-anchored' values (i.e. resp. 38\% and 38\% with definite specificationals, and 35\% and 51\% with indefinite ones). In the reversed variant, however, the value is often either situationally or textually evoked in the prior context and, thus, already given (i.e. $62 \%$ with definite specificationals and $67 \%$ with indefinite ones).

The use of the value in subject position cannot be explained solely in terms of its discourse-familiarity. Rather, what the marked reversed order adds is an emphasis on the value's relation to the discourse context. Partly this includes the information of the value being textually evoked, as in (36).

(36) to ^be an ar: \/istocrat was [@:]\# .^not e:nough to:get you: \/on\# . that was the whole 'purpose of the !st $\backslash$ aff 'system\# you s/ee\# (LLC)

It is commonly argued that the main reason for construing the value as subject is to enable a contrastiveness reading (e.g. Halliday, 1967b; Declerck, 1988). The expression of contrastiveness is only possible, however, when the variable is a definite $\mathrm{NP}$, implying inclusiveness (or uniqueness), but not when the variable is indefinite, in which case it implies the exact opposite, viz. exclusiveness (or non-uniqueness) (Hawkins, 1984).

(37) ^but [@:] "! th \/at isn`t the 'point\# the ^point 'is that yoùve got "! $\{\mathrm{m} \backslash$ asses of $\}$ cr $\backslash$ iticism to $\left\{{ }^{\wedge} \mathrm{r} \backslash\right.$ ead\#\}\# $(\mathrm{LLC})$

(38) it ^ may have been:one of these:students . "!dr \ unk\# - . [@:m] . ^either ! possibly with a:g = irl\#^^coming down_stairs to . !have a !k \iss off her\#. . something of th $\backslash$ at kind\# - and ${ }^{\wedge} \mathrm{dr} \backslash$ unkenly\# . de^ciding:this might 'be a . 'possible ! pl \ace\# . $\underline{\text { \{th } \backslash \text { at might be }\} \text { ! } \backslash \text { one }}$ expla'nation\# - but ${ }^{\wedge} \mathrm{I}$ mean:I don`t "kn/ \ow what the 'explanation 'is\# (LLC)

Therefore, we propose a more general characterisation, in which the reversed order is used to foreground the comparison of the specified value vis-à-vis other 'competitor' values, often mentioned in the prior or following context. While often contrastive (as in [37]), the comparative relation can also be non-contrastive, as with the indefinite specificational clause in (38), where the focal value emphasises the non-exhaustiveness and tentativity associated with the specificational act.

Furthermore, we observed that the value - and by extension the specificational clause as a whole - was introduced quite frequently as a phoric bridge between the context preceding the specificational clause and the context immediately following it. In such cases, the value is not simply textually given in the prior context but has both anaphoric and cataphoric reference. In (39), for instance, the demonstrative value that refers both anaphorically to hitting upon lots of people going round Hyde Park Corner and cataphorically to those big roundabouts. This 'double specification' allows the latter to summarise the situation described in the former in relation to the variable the thing which frightens me.

(39) I go ^down Park L/ane\# and I ^go 'round 'Hyde 'Park C \orner\# and I ^hit_l \ots of people 'going round [@] 'Hyde Park C/orner\# .^that`s the thing which:fr $\backslash$ ightens me\# . is ${ }^{\wedge}$ those big $\mathrm{r} \backslash$ oundabouts\# (LLC)

Finally, the reversed order can also be used when the value is 'brand-new', as in (40). In such cases, the construal of the value as subject serves a rhetorical purpose, to emphasise the value's notable position vis-à-vis other competitor values (e.g. importance, obviousness, etc.).

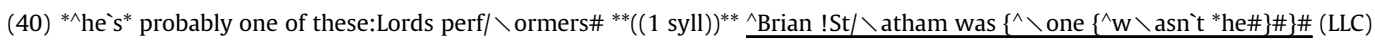

Example (40) is taken from a spontaneous commentary on a cricket match, at a point when the commentators are discussing the Australian cricketer Graham McKenzie, lauded here as one of these Lords performers. Lord's is a well-known London cricket venue and considered the home of cricket. The implication is that anyone who performs exceptionally well at Lord's is considered among the best in the game. In that context, Brian Statham, one of the leading English fast bowlers in 20th century cricket, is newly introduced into the discourse. Like McKenzie he is also among these Lords performers. The high rise-fall on Statham can be glossed here as signalling enthusiasm (Gimson, 1980), awe (O'Connor and Arnold, 1968; Crystal, 1975), special emphasis (Kingdon, 1958), or the speaker's admiration for Brian Statham. In spite of Brian Statham's discoursenewness, the reversed specificational order presents him as relatively hearer-familiar: by virtue of being construed as subject, he serves as reference point for the specificational relation and is the participant from whose vantage point the relation is perceived (Givón, 1984; Langacker, 1999). This assumes the hearers are familiar with the referent. As such, the choice for the 
reversed rather than non-reversed order is exploited here to signal Brian Statham's acclaim and, therefore, to point out the obviousness of mentioning him as one of these Lords performers.

To sum up, we found that, unlike non-reversed ones, reversed specificational clauses are most commonly construed on a single TU. This we attributed to their high degree of discourse-embeddedness, notably due to the typical discourse-familiarity of the value. However, we also showed that the reversal of the variable-value order is used primarily to present the value as if it were predictable from the prior discourse or the immediate circumstances. Such a strategy, we argued, is employed not only when the de-accented value is textually or situationally evoked in the prior context, but also to create a phoric bridge between the prior and following context. In such cases, the demonstrative value has both anaphoric and cataphoric reference. Finally, the examples in which the value was accented in the reversed order were found to emphasise the comparative reference of the value as against competitor values. In definite specificationals, this led to the contrastive meaning typically associated with the marked sentence-initial focus. In indefinite specificationals, the same intonation pattern signalled a non-contrastive comparison by promoting the value as having a special status among the other potential (non-specified) values.

\section{Conclusion}

In this paper we discussed the prosodic realisation of specificational clauses both in their non-reversed and reversed form. Focusing specifically on the interaction between intonation and information structure, we identified critical issues with existing assumptions in the literature. We found notably that only in short non-reversed specificational clauses the focus of information is unequivocally on the value in that it receives the nuclear accent of the specificational sentence (Declerck, 1988: 13).

We showed that only a minority of non-reversed specificational clauses are construed on a single TU and, hence, allow for a straightforward distinction between focus and background. Most non-reversed clauses, however, realise the variable and value on separate TUs. This we argued was motivated by the discourse status and relative (un)predictability of the variable.

Distinguishing between variables ending in a rising tone and in a falling tone, we provided an in-depth descriptive analysis of different meanings associated with the choice of nuclear tone on the variable and how it affects the way the variable's information is presented to the hearer. We pointed out, notably, the much higher incidence of rising tones, especially fallrises, with indefinite variables, which we attributed to their non-exhaustive specification. This allows for multiple values for the same variable and results in a potentially lower degree of epistemic certainty.

Finally, we also looked at reversed specificational clauses. These are generally shorter than non-reversed clauses and typically produced on one TU. Despite this, reversed specificationals were found, contra expectation, to be more likely to have prominence on the variable and not the value. This, we argued, was due to the high incidence of demonstrative values in subject position, which, as Halliday (1967b) noted, tend to de-accent the value. In that respect, we observed that the accenting or de-accenting of the value was related to its link with the prior and following discourse. More specifically, we noted two general patterns with different intonation and information structures of reversed specificationals. First, tonic placement on the value with definite and indefinite specificationals was found to respectively signal a contrastive or non-contrastive comparison of the value vis-à-vis other competitor values. By construing the value as subject and giving it prominence (via the nuclear accent), the speaker thus points out the notable position of the value as against others. Secondly, the absence of a nuclear tone on the value correlated with its discourse-embedding. It was either textually or situationally given in the prior discourse or served in the case of demonstrative subjects to bridge between the prior and following context. Such constructions where the demonstrative has both anaphoric and cataphoric reference allow the speaker to present a value as relatively predictable from the prior discourse, while simultaneously introducing new more specific information. This allows the speaker to pinpoint the exact aspects that sanction the correspondence between the value and the variable.

To conclude, this paper showed that, more often than not, the intonation structure of specificational clauses reflects a more intricate information structure than the mere dichotomy between variable/presupposition and value/focus. In addition, different formal patterns - such as non-reversed vs. reversed constructions; definite vs. indefinite variables - and their associated pragmatic functions were found to correlate with different prosodic realisations. Notably, the utterances' degree of communicative dynamism - that is, the extent to which information contributes to expanding the speaker and hearer's shared knowledge - correlated with differences in tonality, i.e. the segmentation of an utterance in TUs. Finally, different epistemic statuses associated with the definite vs. indefinite variables - that is, the (non-)unique identifiability of their referent - were reflected by different choices of tone, conveying different interpersonal meanings. In sum, we set out, in this paper, that specificational clauses do not function merely as focus-marking constructions (as, for instance, it- and there-clefts, with which they structurally alternate, cf. Njende et al., 2017). Instead, they can express an array of functional meanings, reflected by a variety of prosodic correlates, differing in tonality, tonicity and tone according to the speaker's strategy to present information to the hearer. As a result, this study demonstrates the importance of examining the interplay between syntax, discourse and prosody in explicating the meaning potential of constructions such as specificational clauses.

\section{Acknowledgements}

We would like to thank the two anonymous referees for their constructive and stimulating remarks, which were of much help. The research in this paper came to fruition thanks to the central bilateral agreement between the KU Leuven and Cardiff University; it was carried out as part of a doctoral scholarship funded by the F.R.S.-FNRS. 


\title{
Appendix A. Supplementary data
}

\author{
Supplementary data related to this article can be found at https://doi.org/10.1016/j.pragma.2018.07.013.
}

\section{References}

Akmaijan, A., 1979. Aspects of the Grammar of Focus in English (PhD Dissertation). MIT, Cambridge, MA. Barth-Weingarten, D., 2016. Intonation Units Revisited: Cesuras in Talk-in-interaction. John Benjamins, Amsterdam. Birner, B.J., 1994. Information status and word order: an analysis of English inversion. Language 70 (2), $233-259$. Bolinger, D., 1989. Intonation and its Uses: Melody in Grammar and Discourse. Stanford University Press, Stanford. Brazil, D., 1997. The Communicative Value of Intonation in English. Cambridge University Press, Cambridge.

Cruttenden, A., 1997. Intonation. Cambridge University Press, Cambridge.

Crystal, D., 1969. Prosodic Systems and Intonation in English. Cambridge University Press, Cambridge.

Crystal, D., 1975. The English Tone of Voice: Essays in Intonation, Prosody and Paralanguage. Edward Arnold, London.

Declerck, R., 1988. Studies on Copular Sentences, Clefts, and Pseudo-clefts. Leuven University Press, Leuven.

den Dikken, M., 2006. Specificational copular sentences and pseudoclefts: a case study. In: Everaert, M., van Riemsdijk, H. (Eds.), The Blackwell Companion to Syntax. Blackwell Publishing, Oxford, pp. 292-409.

Dik, S.C., 1997. The Theory of Functional Grammar. Part 1. The Structure of the Clause, second ed. De Gruyter Mouton, Berlin/Boston.

Fox, A., 1986. Dimensions of Prosodic Structure. Work. Pap. Linguist. Phon. 4, 79-127 (University of Leeds).

Gimson, A.C., 1980. An Introduction into the Pronunciation of English. Edward Arnold, London.

Givón, T., 1984. Syntax: a Functional-typological Introduction. John Benjamins, Amsterdam.

Gundel, J., 1988. Universals of topic-comment structure. In: Hammond, M., Moravczik, E., Wirth, J. (Eds.), Studies in Syntactic Typology. John Benjamins, Amsterdam, pp. 209-239.

Gussenhoven, C., 2004. The Phonology of Tone and Intonation. Cambridge University Press, Cambridge.

Halliday, M.A.K., 1967a. Intonation and Grammar in British English. Mouton, The Hague.

Halliday, M.A.K., 1967b. Notes on transitivity and theme in English: Part 2. J. Linguist. 3 (2), 199-244.

Halliday, M.A.K., 1970. A Course in Spoken English: Intonation. Oxford University Press, London.

Halliday, M.A.K., Greaves, W.S., 2008. Intonation in the Grammar of English. Equinox, London.

Hawkins, J.A., 1984. A note on referent identifiability and co-presence. J. Pragmat. 8 (5-6), 649-659.

Hirschberg, J., Ward, G., 1985. Fall-rise intonation and the place of intonational 'meaning' in linguistic theory. In: Proceedings of the Eleventh Annual Meeting of the Berkeley Linguistics Society, vol. 11, pp. 447-458.

Huddleston, R., Pullum, G., 2002. The Cambridge Grammar of the English Language. Cambridge University Press, Cambridge.

Kaltenböck, G., 2005. It-extraposition in English: a functional view. Int. J. Corpus Linguist. 10 (2), 119-159.

Keizer, E., 1997. Referentiality and the representation of predicate nominals. In: Hannay, M., Vester, E. (Eds.), Working with Functional Grammar: Descriptive and Computational Applications, pp. 145-166. Dordrecht.

Kimps, D., Davidse, K., Cornillie, B., 2014. A speech function analysis of tag questions in British English spontaneous dialogue. J. Pragmat. 66, 64-85.

Kingdon, R., 1958. The Groundwork of English Intonation. Longmans, London.

Knowles, G., 1984. Various strategies in intonation. In: Gibbon, D., Richter, H. (Eds.), Intonation, Accent, and Rhythm: Studies in Discourse Phonology. de Gruyter, Berlin/New York, pp. 226-242.

Ladd, R., 1980. The Structure of Intonational Meaning: Evidence from English. Indiana University Press, Bloomington.

Ladd, R., 2008. Intonational Phonology, second ed. Cambridge University Press, Cambridge.

Lambrecht, K., 1994. Information Structure and Sentence Form: Topic, Focus, and the Mental Representations of Discourse Referents. Cambridge University Press, Cambridge.

Langacker, R.W., 1999. Grammar and Conceptualization. De Gruyter Mouton, Berlin/Boston.

Mikkelsen, L., 2005. Copular Clauses: Specification, Predication and Equation. John Benjamins, Amsterdam/Philadelphia.

Njende, N., Davidse, K., Ghesquière, L., 2017. Specificational it- and there-clefts with quantified NPs as value. In: Paper Presented at LxGr2017. Edge Hill, 10 June 2017.

O'Connor, J.D., Arnold, G.F., 1968. Intonation of Colloquial English: a Practical Handbook. Longmans, London.

O'Grady, G., 2017. Theme and prosody: redundancy or meaning making? Engl. Text Constr. 10 (2), $274-297$.

O'Grady, G., 2010. A Grammar of Spoken English Discourse: the Intonation of Increments, Continuum Studies in Theoretical Linguistics. Continuum, London.

Patten, A.L., 2016. Well-formed lists: specificational copular sentences as predicative inversion constructions. Engl. Lang. Ling. 22 (1), $77-99$.

Patten, A.L., 2012. The English It-Cleft: a Constructional Account and a Diachronic Investigation. De Gruyter Mouton, Berlin/New York.

Pierrehumbert, J., Hirschberg, J., 1990. The meaning of intonational contours in the interpretation of discourse. In: Cohen, P.R., Morgan, J.L., Pollack, M.E. (Eds.), Intentions in Communication. MIT Press, Cambridge, MA, pp. 271-311.

Prince, E.F., 1981. Towards a taxonomy of given-new information. In: Cole, P. (Ed.), Radical pragmatics. Academic Press, New York, pp. $281-297$.

Prince, E.F., 1992. The ZPG letter: subjects, definiteness and information status. In: Mann, W.C., Thompson, S.A. (Eds.), Discourse Description: Diverse Linguistic Analyses of a Fund-raising Text. John Benjamins, Amsterdam, pp. 295-325.

Sharp, A.E., 1953. Falling-rising intonation patterns in English. Phonetica 2 (3-4), 127-152.

Stalnaker, R., 2002. Common ground. Ling. Philos. 25 (5-6), 701-721.

Tench, P., 1988. The Roles of Intonation in English Discourse. Peter Lang. ed., Frankfurt am Main.

Tench, P., 1996. The Intonation Systems of English. Cassell, London.

Tench, P., 2003. Processes of semiogenesis in English intonation. Funct. Lang. 10 (2), 209-234.

The Independent, 2018. Trump Leaves Middle East Giants Iran and Israel on the Brink of a Deadly Duel. Last accessed on 16 June 2018. https://www. independent.ie/world-news/middle-east/trump-leaves-middle-east-giants-iran-and-israel-on-the-brink-of-a-deadly-duel-36899234.html.

Van Praet, W., Davidse, K., 2016. Revisiting the typology of English copular clauses: ascription and specification in categorizing and identifying clauses. Leuven Work. Pap. Linguist. 4 (19), 1-32.

Watt, D.L.E., 1992. An instrumental analysis of English nuclear tones. In: Tench, P. (Ed.), Studies in Systemic Phonology. Pinter Publishers, London/New York, pp. 135-160.

Wout Van Praet obtained his MA in Linguistics from the University of Leuven in 2014. He also holds the degree of MSc in "Mind, Language and Embodied Cognition" from the University of Edinburgh (2015). He is currently working on his PhD at the University of Namur and the University of Leuven, focusing specifically on indefinite specificational clauses in English and their surrounding copular system.

Dr Gerard O'Grady is a Reader at the Centre of Language and Communication Research at Cardiff University. He is the author and editor of 5 books including $A$ Grammar of Spoken English Discourse, London: Continuum, 2010. His recent work examines differences between language as process and product and the information structure of spoken discourse. 